\title{
RECOLLECTIONS
}

\section{Calorimetric studies of biopolymers}

\author{
JULIAN M. STURTEVANT \\ Department of Chemistry and Molecular Biophysics \& Biochemistry, Yale University, New Haven, Connecticut 06520-8107
}

In this autobiographical sketch I propose to tell how, early in my career, I stumbled into calorimetry and became so attached to it that I have remained active in it ever since, with approximately two-thirds of all my publications being in some way connected with calorimetry.

I obtained a Ph.D. in organic chemistry from Yale University in 1931, and went directly into teaching elementary organic chemistry. This was my major pedagogical activity until 1943, when I went to M.I.T. to work on radar during World War II in the Radiation Laboratory. But even before 1931 I realized that I was more interested in the physicochemical aspects of organic chemistry than in straight organic. In common with other young scientists, I was attracted by theoretical activities. Theory seemed to me to be a much more attractive route to scientific advances than experiment. I therefore made a few attempts in this direction. My first attempt had to do with the rotation of polar groups in organic compounds, treated according to wave mechanics. In this work I received much help from Henry Margenau of the Physics Department here at Yale. Then I tackled the problem of orientation effects in bimolecular ionic reactions (Sturtevant, 1935), this time being greatly assisted in mathemat-

Reprint requests to: Julian M. Sturtevant, Department of Chemistry, Yale University, New Haven, Connecticut 06520-8107.

Julian M. Sturtevant received a bachelor's degree from Columbia College in New York in 1927 and a Ph.D. degree in organic chemistry from Yale University in 1931. He was then appointed as an Instructor in Chemistry at Yale and remained in that department until "retirement" in June 1977, except for three years at the Radiation Laboratory at M.I.T. during World War II and six sabbatical leaves [University of Cambridge; University of Adelaide, Australia; University of California, San Diego (twice); University of Washington, and Stanford University]. He was a von Humboldt Senior Scientist at the University of Regensburg, Germany, in 1978-79. He still has an active research laboratory at Yale supported by the university and by grants from the National Institutes of Health and the National Science Foundation. Dr. Sturtevant is a member of the National Academy of Sciences, a fellow of the American Association for the Advancement of Science, the American Academy of Arts and Sciences, and the Connecticut Academy of Science and Engineering. He received honorary doctorates from Illinois College in 1962 and from the University of Regensburg in 1978. He received the Hugh Huffman award of the U.S. Calorimetry Conference in 1964, the William Clyde DeVane medal of Yale in 1978, the Innovator in Biochemistry award of the Medical College of Virginia in 1984, and the Wilbur Cross award of Yale in 1987.

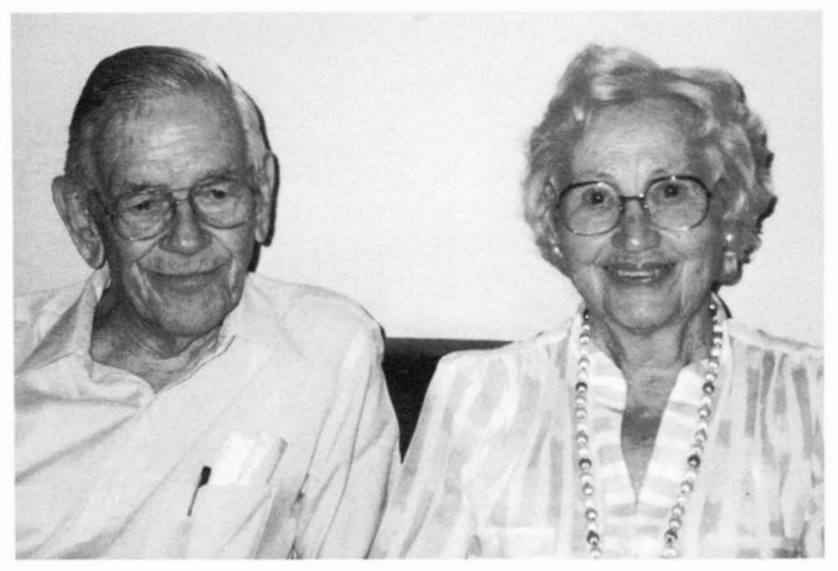

Julian and Elizabeth Sturtevant

ical problems by Lars Onsager of the Chemistry Department. My third theoretical effort had to do with a heat transfer problem of interest in connection with a cylindrical calorimeter of the form that I was then concerned with developing, and again I was helped in mathematical difficulties by Lars Onsager.

After these episodes of having received important mathematical help in my theoretical attempts, I decided that I was not destined to be a theoretical chemist. I then turned to experimental research and started measuring the rates of organic reactions. One of my first attempts involved the alkaline hydrolysis of organic esters, and I decided to use dilatometry, a method very successfully used by Kai Linderström-Lang of the Carlsberg Laboratory in Copenhagen and by various other people.

It soon became evident that my measurements were being significantly perturbed by the large heat of reaction despite the immersion of the dilatometer in an aqueous thermostat. It therefore seemed that I could increase the sensitivity of my measurements if I were to convert the dilatometer to a small Dewar flask with an emergent capillary. The experiments with this jacketed dilatometer were not successful, primarily because of the remaining slow heat transfer between the reacting solution and the water bath. It was evident that the dilatometer should be really 
adiabatic, but then, if this situation were achieved, it would be possible to use the temperature change due to the reaction heat to determine not only the rate of the reaction but also its change in enthalpy. In other words, the dilatometer should be converted to an adiabatic calorimeter, with the glass cell replaced by a metal cell and the capillary removed (Sturtevant, 1937). I had shown by heat transfer calculations that the time lag in a calorimeter of the proposed design would be less than $15 \mathrm{~s}$, so that it would be safe to use it with reactions having half times of 10 min or more. The cell of small diameter was constructed of platinum and was enclosed in a copper adiabatic jacket. Copperconstantan thermopiles were used for all temperature measurements, including the temperature of the reaction cell, the cold junctions of this thermel being immersed in a "cold calorimeter," as originally introduced by W.P. White. The significant temperature readings were thermopile outputs evaluated by means of a thermo-free potentiometer and a wall-mounted galvanometer scale viewed through a telescope. Readings were made every minute or half-minute, and were recorded manually. Such data collections were obviously far more difficult and timeconsuming in those days than they are now, especially for a neophyte with very limited financial support.

This calorimeter was tested by a series of measurements of the rate and heat of "inversion" (hydrolysis) of sucrose at $25^{\circ} \mathrm{C}$ by several different concentrations of $\mathrm{HCl}$, and of the rate and heat of the decomposition of diacetone alcohol at $25^{\circ} \mathrm{C}$ and $30^{\circ} \mathrm{C}$ by various concentrations of $\mathrm{NaOH}$. The former reaction is exothermic and the latter is endothermic. I was quite pleased when I learned some 55 years later that a very careful study of the sucrose inversion at the National Institute of Standards and Technology had given for the enthalpy of this reaction at $25^{\circ} \mathrm{C}$ a value agreeing with mine to within $0.6 \%$, of course a largely fortuitous agreement.

I certainly did not appreciate at this stage in my calorimetric career the wide-ranging importance of measurements of the heats of chemical reactions. My attention thus far had been restricted to rather simple reactions, and heats for such processes were available from equilibrium measurements by way of the van't Hoff equation or from bomb or combustion calorimetry.

In the early days of biochemical and organic chemical calorimetry, calorimeters generally had rather short lives because of the widespread desire to devise improved instrumentation and methodology in the developing field. Accordingly, I, too, developed a new calorimeter which included provision for initiating the reaction by mixing the reactants within the calorimeter and stirring the contents. The reaction cell, with a volume of about $150 \mathrm{~mL}$, and the dilution cup, with a volume of about $10 \mathrm{~mL}$, were constructed of tantalum. The dilution cup, which was closed at the bottom with gold or other suitable foil, was equipped with a platinum-iridium bellows that could be expanded with nitrogen pressure to cut out the foil closure. Stirring was accomplished by rocking the whole assembly, including the adiabatic jacket and the cold calorimeter housing the reference thermocouple junctions.

This calorimeter was used initially to determine the rates and heats of the mutarotation of $\alpha$-and $\beta$-D-glucose. The change in enthalpy on converting the $\alpha$ to the $\beta$ form at $25^{\circ}$ is only -278 $\mathrm{cal} \mathrm{mol}^{-1}$. It was also employed in determinations of the heats of dilution of $\mathrm{HCl}$ and $\mathrm{NaOH}$ over wide concentration ranges, and of glycine, and the heats of ionization of glycine and alanine. These measurements were being made as the start of a pro- gram of thermochemical work on amino acids and proteins, the importance of which had been pointed out to me by John Edsall of Harvard. Edsall had for some time been interested in the thermodynamics of biochemical processes, and was therefore well aware of the paucity of data in this area, and the importance of obtaining quantitative energy data by means other than by combustion, or bomb, calorimetry.

The wide applicability of calorimetric measurements to broaden the thermodynamic data concerning relatively complex molecules and their reactions, and the importance of such broadening, was by this time evident even to me, and my attention to calorimetry became the central theme of my research.

As mentioned earlier, in the long period before the development of commercially available solution calorimeters, calorimetrists usually spent large fractions of their time building new, and hopefully improved, instruments. I was no exception to this rule and, in 1951, published (Buzzell \& Sturtevant, 1951) the details of a more elaborate apparatus containing twin calorimeters with automatically controlled electrical feedback to maintain zero temperature difference between the two calorimeter cells. Circuits that today would be considered to be extremely crude and bulky were designed to square, integrate, and record the feedback current. This instrument was used over a period of many years to measure the enthalpy changes in a wide variety of biochemically important processes, including the isothermal denaturation of pepsin by changes in $\mathrm{pH}$; the hydrolysis of peptide bonds (Dobry et al., 1952); the reaction between trypsin and soybean trypsin inhibitor; the hydrolysis of inorganic and organic phosphates; the polymerization and clotting of fibrin monomers (Laskowski et al., 1955); the denaturation of DNA; the reaction between polyriboadenylic acid and polyribouridylic acid; and many others.

I was diverted from thermochemistry for a brief period by stopped-flow kinetic measurements on various enzymic processes such as the dehydrogenation of L-lactate by cytochrome b2. Then, in 1966, following a suggestion of George Rawitscher, at that time in the Physics Department at Yale, that measurements of the heat capacity of a protein in solution over a range of temperatures should lead by integration to the evaluation of the enthalpy change in a thermally induced process such as denaturation, we built (Danforth et al., 1967) a differential scanning calorimeter (DSC). Such an instrument should be of particular interest in giving a direct evaluation of the enthalpy difference between the native, folded form of a protein, or of a nucleic acid, and the denatured, unfolded form. Although these two states would be observed at different temperatures, so that a permanent change in heat capacity, $\Delta C_{p}$, might well be involved with an accompanying change in enthalpy, nevertheless the method would have the advantage of not involving a chemical denaturing agent. DSC over the past quarter century has supplied much of our current information concerning the intramolecular energetics of proteins and nucleic acids, expressed in terms of enthalpies and entropies as well as free energies (Sturtevant, 1994).

We made much use of our home-built DSC for several years, despite the fact that to cool it down after a scan we had to fill the thermostatic bath with ice and water, which meant that we were effectively limited to one experiment per day. Among the processes studied with this instrument were the helix-coil transitions of poly A-poly U complexes, of the copolymer of deoxyadenylic acid and deoxythymidylic acid, of aqueous DNA, and 
of $\mathrm{rA}_{7} \mathrm{U}_{7}$ (Breslauer et al., 1976); the unfolding of ribonuclease $A$; and the phase transitions of phospholipids.

In those days, there were very few laboratories where thermochemical research on biochemical systems could be carried out, and it was therefore not surprising that we had frequent collaborations with scientists from other laboratories, some initiated by us, but more proposed to us by others. It was a very satisfactory situation in which, among numerous other advantages, we were able to profit from the skills others had developed in the preparation and purification of proteins, nucleic acids, and lipids, skills that are still notably absent from my laboratory.

At about this, time I spent one of our Yale one-term sabbaticals, which came every three years, at the University of California, San Diego, in the laboratory of Jon Singer. There I was fortunate to share an office with Stan Gill from the University of Colorado, also on sabbatical. I had recently received for free trial from Beckman Instruments one of their heat-leak reaction calorimeters (Model 190) based on the design of C. Kitzinger and T.H. Benzinger. In this instrument, the enthalpy change in a reaction is detected by a thermopile through which essentially the entire heat flow to or from a massive heat sink takes place. Stan had recently built in his laboratory a flow calorimeter in which solutions of two reactants are pumped at accurately known rates through a mixing chamber and a length of flow tubing such that the entire reaction heat is evolved or absorbed within the calorimeter, and he thought that the thermopile and heat sink construction of the Benzinger calorimeter could be adapted to form such a flow calorimeter.

I accordingly wrote to Beckman asking for dimensional information concerning their instrument, and their reply was to send two engineers to La Jolla to consult with me. The result of this visit was a trial instrument with teflon flow tubing, which I put through extensive trials after my return to New Haven. These trials were so successful that Beckman decided to make an instrument with platinum flow tubing, which we used for several years with much success. Beckman made one or two more of these instruments, which they sold, but for some reason unknown to me, they abandoned further activities in the field of calorimetry.

We applied the flow calorimeter to thermodynamic studies of a wide variety of processes, including the mixing of pure organic liquids (Sturtevant \& Lyons, 1969), the binding of S-peptide to S-protein to form ribonuclease $S^{\prime}$ (Hearn et al., 1971), the trypsin-catalyzed activation of chymotrypsinogen $A$, the binding of $p$-nitrophenyl haptens to rabbit antibodies (Barisas et al., 1971), the enthalpies of hydrolysis of phosphate esters (Gerlt et al., 1975), the binding of flavin adenine dinucleotide to $D$-amino acid oxidase, and many others.

In 1975 or thereabouts, the situation with respect to availability of calorimeters began to improve. We purchased a batch calorimeter developed by Ingemar Wadsö and his colleagues in Lund, Sweden, and used it in a few projects. An excellent DSC, designated the DASM-1M, was designed by Peter Privalov and his colleagues at the Institute for Protein Research in Puschino, Moscow Region, Russia, and I was able to purchase one of these at a very favorable price. We thus never made any further use of the awkward DSC that we had built. After a few years, an improved DSC, the DASM-4, also made in Puschino, became available, and again we were offered a very favorable price and purchased one. Then, after a few more years, an excellent DSC, the $\mathrm{MC}-2$, was developed and marketed in America and elsewhere by Microcal, Inc., of Northampton, Massachusetts. Fortunately for me, one of these instruments was placed in my laboratory on indefinite loan by the founder of Microcal, John Brandts, of the University of Massachusetts. An outstanding feature of the MC-2 is that it is very effectively controlled by a dedicated computer with very useful software.

It soon became evident that we could not keep three scanning calorimeters in active use so we scrapped the DASM-1M, on which we had by then made many electronic changes for a variety of reasons. My postdoctoral associates and I have made continuous use of our two DSC equipments (Sturtevant, 1987), to a large extent on studies of mutant forms of proteins kindly supplied by colleagues in this country and abroad.

We continued using the flow calorimeter mentioned earlier, and a modification thereof, until 1988. In that year, an excellent isothermal titration calorimeter, the OMEGA, was developed by Microcal (Wiseman et al., 1989) and again one of these was placed in my laboratory on indefinite loan. We have, therefore, had no stimulus to attempt any local construction of any type of calorimetric equipment, and have been able to devote all of our thermodynamic efforts to experimental and interpretive activities, a situation we appreciate greatly. It has been very interesting to see the rapid increase in recent years in the application of calorimetry to the direct determination of the enthalpy changes and changes in heat capacity accompanying biochemical processes. In view of the facts that the change in heat capacity, $\Delta C_{p}$, controls the temperature variation of the changes in enthalpy, $\Delta H$, entropy, $\Delta S$, and Gibbs free energy, $\Delta G$, for any chemical process, and that calorimetry supplies the most direct route for evaluating $\Delta C_{p}$, it is not surprising that the importance of calorimetry is increasingly recognized.

My research program at Yale, up until 1977 when I "retired" at the then mandatory age of 68 , was largely maintained by a host of graduate students and postdoctoral associates too numerous to list. Since then, my coworkers have been entirely postdoctoral associates, again constituting a long list. I am deeply indebted to all these people, not only for the results they produced and the ideas they contributed, but also for how interesting and stimulating life in the laboratory with them has always been. Our research has been well supported by Yale University, and by the National Institutes of Health and the National Science Foundation ever since these two agencies were first established.

\section{References}

Barisas BG, Sturtevant JM, Singer SJ. 1971. Thermodynamics of the binding of haptens to rabbit anti-2,4-dinitrophenyl antibodies. Biochemistry 10:2816-2821.

Breslauer K, Sturtevant JM, Tinoco I. 1976. Calorimetric and spectroscopic investigations of the helix-coil transition of $\mathrm{rA}_{7} \mathrm{U}_{7}$. J Mol Biol 99:549565 .

Buzzell A, Sturtevant JM. 1951. A new calorimetric method. $J$ Am Chem Soc 73:2454-2458.

Danforth R, Krakauer H, Sturtevant JM. 1967. Differential calorimetry of thermally induced processes in solution. Rev Sci Instruments 38:484-487.

Dobry A, Fruton IS, Sturtevant JM. 1952. Thermodynamics of hydrolysis of peptide bonds. J Biol Chem 195:149-154.

Gerlt JA, Sturtevant JM, Westheimer FH. 1975. The enthalpies of hydrolysis of acyclic, monocyclic and glycoside cyclic phosphate diesters. $J$ Biol Chem 250:5059-5067.

Hearn RP, Richards FM, Sturtevant JM, Watt GD. 1971. Thermodynamics of the binding of S-peptide to S-protein to form ribonuclease $\mathrm{S}^{\prime}$. Biochemistry 10:806-817.

Laskowski M Jr, Donnelly TH, Scheraga HA, Sturtevant JM, 1955. Heats 
of polymerization and clotting of fibrin monomer. $\mathrm{J} \mathrm{Am} \mathrm{Chem} \mathrm{Soc}$ 77:6168-6172.

Sturtevant JM. 1935. Orientation effects in biomolecular ionic reactions. J Chem Phys 3:295-299.

Sturtevant JM. 1937. Calorimetric investigations of organic reactions. I. Apparatus and method. The inversion of sucrose and the decomposition of diacetone alcohol. J Am Chem Soc 59:1528-1537.

Sturtevant JM. 1987. Biochemical applications of differential scanning calorimetry. Annu Rev Phys Chem 38:463-488.
Sturtevant JM. 1994. The thermodynamic effects of protein mutations. Curr Opin Struct Biol 4:69-78.

Sturtevant JM, Lyons PA. 1969. Application of flow calorimetry to the determination of the enthalpies of mixing of organic liquids. J Chem Thermodynamics 1:201-209.

Wiseman T, Williston S, Brandts J, Lin L. 1989. Rapid measurement of binding constants and heats of binding using a new titration calorimeter. Anal Biochem 179:131-137. 